\title{
Cerebrospinal Fluid Biomarkers Are Associated With Glial Fibrillary Acidic Protein and $\alpha$ ll-spectrin Breakdown Products in Brain Tissues Following Penetrating Ballistic-Like Brain Injury in Rats
}

\author{
Kristen E. DeDominicis*, Hye Hwang, Casandra M. Cartagena, Deborah A. Shear and \\ Angela M. Boutté
}

Brain Trauma Neuroprotection and Neurorestoration Branch, Center for Military Psychiatry and Neuroscience, Walter Reed Army Institute of Research, Silver Spring, MD, United States

\section{OPEN ACCESS}

Edited by:

Firas H. Kobeissy,

University of Florida, United States

Reviewed by:

Eric Peter Thelin,

University of Cambridge,

United Kingdom

Shoji Yokobori,

Nippon Medical School, Japan

Ralph George Depalma,

U.S. Department of Veterans Affairs,

United States

*Correspondence:

Kristen E. DeDominicis

kristen.dedominicis@gmail.com

Specialty section: This article was submitted to

Neurotrauma,

a section of the journal

Frontiers in Neurology

Received: 01 March 2018 Accepted: 05 June 2018

Published: 04 July 2018

Citation:

DeDominicis KE, Hwang $H$,

Cartagena CM, Shear DA and Boutté AM (2018) Cerebrospinal Fluid Biomarkers Are Associated With Glial

Fibrillary Acidic Protein and all-spectrin Breakdown Products in Brain Tissues Following Penetrating Ballistic-Like Brain Injury in Rats.

Front. Neurol. 9:490. doi: 10.3389/fneur.2018.00490
Treatments to improve outcomes following severe traumatic brain injury (TBI) are limited but may benefit from understanding subacute-chronic brain protein profiles and identifying biomarkers suitable for use in this time. Acute alterations in the well-known TBI biomarkers glial fibrillary acidic protein (GFAP), all-spectrin, and their breakdown products (BDPs) have been well established, but little is known about the subacute-chronic post-injury profiles of these biomarkers. Thus, the current study was designed to determine the extended profile of these TBI-specific biomarkers both in brain tissue and cerebral spinal fluid (CSF). Protein abundance was evaluated in brain tissue samples taken from regions of interest and in CSF at 24 h, 3 days, 7 days, 1 month, and 3 months following severe TBI in rats. Results showed increased full length GFAP (GFAP-FL) and GFAP-BDPs starting at $24 \mathrm{~h}$ that remained significantly elevated in most brain regions out to 3 months post-injury. However, in CSF, neither GFAP-FL nor GFAP-BDPs were elevated as a consequence of injury. Regional-specific reduction in $\alpha$ ll-spectrin was evident in brain tissue samples from $24 \mathrm{~h}$ through 3 months. In contrast, SBDP-145/150 was robustly elevated in most brain regions and in CSF from $24 \mathrm{~h}$ through 7 days. Correlation analyses revealed numerous significant relationships between proteins in CSF and brain tissue or neurological deficits. This work indicates that TBI results in chronic changes in brain protein levels of well-known TBI biomarkers GFAP, $\alpha$ ll-spectrin, and their BDPs and that SBDP-145/150 may have utility as an acute-chronic biomarker.

Keywords: traumatic brain injury, biomarker, glial fibrillary acidic protein, $\alpha$ ll-spectrin, breakdown product, penetrating ballistic-like brain injury, subacute, chronic

\section{INTRODUCTION}

Severe penetrating traumatic brain injury (TBI) from gunshot wounds is of concern to both military and civilians alike. Approximately 5,000 penetrating TBI cases were reported from 2000 to 2017 among military personnel (1). Additionally, a high incidence of gun violence persists among civilian populations (2). Severe TBI patients are at risk for 
mortality and reduced life expectancy (3-5) and the incidence and prevalence of chronic debilitating disability among severe TBI patients are substantial (6-8). Further, the lifetime costs of long-term treatment and care for a severely injured TBI patient and the stresses placed on family caretakers are devastating. Neurosurgical interventions may provide benefits such as reduced intracranial pressure (9) and decreased mortality (10). Yet, clinically effective treatments for treating severe TBI at the molecular level remain somewhat limited, which constitutes a critical gap in patient care. Increased understanding of acute-chronic molecular events in multiple brain regions following severe TBI is important to provide guidance regarding targeted solutions for both acute and chronic treatments.

Traumatic brain injury results in a primary injury characterized by immediate destruction of brain tissue with hemorrhage followed by a complex secondary injury cascade during which there is an influx of intracellular calcium (11-13) and subsequent activation of calcium-activated, non-lysosomal proteases such as calpain-II (14). Glial fibrillary acidic protein (GFAP), an intermediate filament protein expressed abundantly by astrocytes that is increased in multiple TBI models during reactive astrogliosis $(15,16)$, is a well described substrate of calpain-II mediated proteolysis. Another key substrate, non-erythroid $\alpha \mathrm{II}$-spectrin, is a neuronal scaffolding protein expressed abundantly in axons and pre-synaptic terminals (17). Cleavage of GFAP and $\alpha$ II-spectrin by calpain-II results in generation of breakdown products (BDPs) $(18,19)$. These proteins are highly enriched throughout the CNS and are detectable in biofluids following TBI. Therefore, these proteins and their BDPs have garnered significant interest for their potential utility as indicators of TBI-mediated astrogliosis and neuronal cell death during secondary brain injury cascades and as peripheral biomarkers associated with focal injury severity and negative outcomes (20-22). It should be noted, however, that astrogliosis is not necessarily a maladaptive process and may provide benefit following TBI (23).

The increased presence of these proteins and their BDPs in brain tissues has been well described following acute TBI (2427). However, these observations may persist chronically and differ across brain regions and CSF. GFAP-BDPs (28) and GFAP autoantibodies (29) are increased in blood derived from chronic TBI patients. CSF levels of $\alpha$ II-spectrin breakdown products (SBDPs) remain elevated compared to controls at 5-7 days after severe penetrating TBI (20), suggesting this increase may continue past the acute timeframe. Additionally, the relative abundance of calpain-II is rarely described within matching cohorts over an extended period although it is a key mediator of BDP generation. Longitudinal characterization of these proteins in brain tissues would provide vital information regarding the duration and extent of secondary injury following severe TBI, while temporal alteration of these proteins in biofluids may prove useful as biomarkers to track injury progression. Further, defining how this secondary injury cascade differs across brain regions that are either proximal or distal to the injury trajectory site as a consequence of both time and injury is of critical importance.
The goal of the current study was to temporally define the abundance of GFAP, $\alpha$ II-spectrin, and their associated BDPs in specific brain tissue regions and CSF following TBI. Injuries were induced using a rat model of penetrating ballistic-like brain injury (PBBI), which mimics the permanent injury tract and temporary cavity generated from a penetrating ballistic round (30-32) and results in well-described pathophysiology as well as behavioral impairment (33-35). This study also explores protein levels of calpain-II in brain tissues. We report that calpainII mediated proteolysis in brain tissues persists well past the acute post injury window and into the chronic time frame following PBBI. Furthermore, we present evidence that detection of $\alpha$ II-spectrin BDPs is prominent in cerebral spinal fluid throughout acute-subacute injury and has value as a correlative biomarker for these same fragments in brain tissues.

\section{MATERIALS AND METHODS}

\section{Animals}

Adult male Sprague-Dawley rats (Charles River Laboratories, Raleigh, VA, United States) weighing $\sim 250-300$ g were used in this study. All rats were singly housed with a $12 \mathrm{~h}$ normal light/dark cycle. Surgical procedures were performed under isoflurane anesthesia ( $2-5 \%$ delivered in oxygen). For terminal bio-sample collections at 24 hours (h), 3 days (d), 7 days, 1 month $(\mathrm{m})$, and $3 \mathrm{~m}$ following injury, rats were deeply anesthetized with $70 \mathrm{mg} / \mathrm{kg}$ ketamine and $6 \mathrm{mg} / \mathrm{kg}$ xylazine. Research was conducted under an approved animal use protocol in an AAALACi accredited facility in compliance with the Animal Welfare Act and other federal statutes and regulations relating to animals and experiments involving animals and adheres to principles stated in the Guide for the Care and Use of Laboratory Animals, NRC Publication, 2011 edition.

\section{Brain Injury Procedures}

The WRAIR PBBI model captures the injury trajectory and temporary cavity generated by energy dissipation from a highenergy bullet wound to the head (30). Unilateral frontal PBBI was induced as previously described (34). Briefly, anesthetized rats were placed on a stereotaxic frame. Following craniotomy ( $+4.5 \mathrm{~mm}$ antero-posterior, $+2 \mathrm{~mm}$ medio-lateral from bregma), a probe was inserted through the right frontal cortex and striatum to $1.2 \mathrm{~cm}$ from dura and a computer-controlled pulse generator was activated to rapidly inflate and deflate a balloon on the end of the probe, creating a temporary cavity equivalent to $10 \%$ brain volume. Probe injured rats received identical procedures except balloon inflation/deflation. Sham rats received craniotomy without probe insertion.

\section{Neuroscore Assessment}

Neurological deficits were assessed using a modified testing paradigm (36) at $24 \mathrm{~h}$ following injury or sham manipulation by an experimenter who was blinded to the injury condition. A composite score was generated from four separate parameters: contralateral forelimb flexion, body upward curling behavior during tail suspension, open-field circling behavior, and impaired resistance to lateral push. Each parameter was scored from 0 
(normal) to 3 (severely impaired) for a maximum composite score of 12 for each animal.

\section{Cerebral Spinal Fluid and Brain Tissue Collection and Preparation}

A 4-cm midline incision was made from $0.5 \mathrm{~cm}$ anterior to the interauricular line. The atlanto-occipital dura mater was exposed by separating the nuchal muscles and CSF was collected with a 30-gauge syringe needle through the membrane. CSF was stored on ice, supplemented with 1xHALT protease/phosphatase inhibitor mix (Thermo Fisher Scientific, Grand Island, NY, United States), and centrifuged at $1,400 \mathrm{~g}$ for $10 \mathrm{~min}$ at $4^{\circ} \mathrm{C}$. The resulting cell free $\mathrm{CSF}$ was stored at $-80^{\circ} \mathrm{C}$ until use. To increase the concentration of antigens in CSF, the entire collected volume of each CSF sample was concentrated with Amicon Ultra Centrifugal Filter Units with Ultracel-3 membranes (EMD Millipore, Billerica, MA, United States) for $30 \mathrm{~min}$ at $14,000 \times \mathrm{g}$ at $4^{\circ} \mathrm{C}$ (normalization method presented in "Statistical Analysis"). Ipsilateral brain tissues were washed with $0.9 \%$ saline and dissected on ice to isolate the frontal cortex, striatum, hippocampus, and residual midbrain. All tissues were flash-frozen in liquid nitrogen. Concentrated CSF and flashfrozen brain tissues were stored at $-80^{\circ} \mathrm{C}$ until use.

\section{Western Blotting}

Brain tissues were sonicated in 1xRIPA buffer containing 1xHALT protease/phosphatase inhibitors (Thermo Fisher Scientific, Grand Island, NY, United States). Protein concentrations were determined using the BCA assay kit (Thermo Fisher Scientific, Grand Island, NY, United States) and crude homogenates were stored frozen until use. All samples for western blotting were prepared in $1 \mathrm{x}$ LDS NuPAGE sample buffer and $250 \mu \mathrm{M}$ DTT and denatured for $5 \mathrm{~min}$ at $95^{\circ} \mathrm{C}$. Equivalent amounts of total protein $(20 \mu \mathrm{g}$ for calpain-II, $25 \mu \mathrm{g}$ for GFAP and $\alpha$ II-spectrin) for tissue samples or $10 \mu \mathrm{L}$ of concentrated CSF prepared as described above were loaded onto 12\% (GFAP in tissue) or $4-12 \%$ bis-tris gels (GFAP in CSF, $\alpha I I-s p e c t r i n$ in tissues and CSF, calpain-II in tissues) for separation by SDS-PAGE (Invitrogen NuPAGE, Carlsbad, CA, United States). Proteins were transferred to PVDF membranes and blocked in $5 \%$ milk in 1xPBS (GFAP and $\alpha$ II-spectrin in tissues) or to nitrocellulose membranes and blocked with Odyssey Blocking Buffer - PBS (GFAP and $\alpha$ II-spectrin in CSF, calpain-II in tissues; LI-COR Biosciences, Inc., Lincoln, NE, United States). Individual membranes were probed with the following primary antibodies: GFAP (ab7260, Abcam, Cambridge, MA, United States), $\alpha I I-$ spectrin (in tissues: MAB1622, EMD Millipore, Billerica, MA, United States; in CSF: BML-FG6090, ENZO, Farmingdale, NY, United States), Calpain-II - Large Subunit (\#2539, Cell Signaling Technology, Danvers, MA, United States), and washed with phosphate buffered saline containing $0.01-0.1 \%$ Tween 20 (PBST). For tissue GFAP and $\alpha$ II-spectrin blots, membranes were incubated with horseradish peroxidase (HRP)-linked secondary antibodies and bands were detected with Clarity Western ECL (Bio-Rad, Hercules, CA, United States). Blots were visualized and quantified using the ImageQuant LAS4000 and ImageQuant TL v7.0 software (GE Healthcare, Pittsburgh, PA, United States).
For calpain-II and GFAP and $\alpha$ II-spectrin blots of CSF, InfraRed (IR)-Dye labeled secondary antibodies were used to visualize bands on the Odyssey CLx imaging system (LI-COR Biosciences, Lincoln, NE, United States) and bands were quantified using ImageStudio v5.2 software (LI-COR Biosciences, Lincoln, NE, United States).

\section{GFAP Electro-Chemiluminescent Enzyme-Linked Immunosorbent Assay (ELISA)}

Concentrated CSF samples were evaluated for GFAP content using an in-house assay developed for detection with the Mesoscale Discovery (MSD) platform (37). Samples and standards were loaded in duplicate. Samples were diluted in $1 \times$ PBS, $\mathrm{pH} 7.8$ (Bio-Rad, Hercules, CA, United States) then incubated in plates manually coated with $25 \mu \mathrm{g} / \mathrm{mL}$ polyclonal anti-GFAP (ab7260, Abcam, Cambridge, MA, United States) in 1xPBS, pH 7.8. Plates were then incubated with mixed monoclonal anti-GFAP detection antibodies (BD556330, BD Biosciences, San Jose, CA, United States) and anti-mouse sulfo-tag antibody (MSD, Rockville, MD, United States) at $0.5 \mu \mathrm{g} / \mathrm{mL}$ each in $0.5 \%$ Blocker B prepared in $1 \mathrm{xPBS}, \mathrm{pH} 7.8$. Protein content was derived from standard curves using recombinant human GFAP protein in PBS (Banyan Biomarkers, Alachua, FL, United States; standard range: $0.156-10 \mathrm{ng} / \mathrm{mL}$ ) fit by a cubic third order polynomial function. Values derived from PBS were used as blanks and subtracted from all samples. Analyte quantitation $(\mathrm{ng} / \mathrm{mL})$ was determined by electro-chemiluminescent signal with a Meso QuickPlex SQ120 (Meso Scale Discovery, Rockville, MD, United States).

\section{Data Management and Statistical Analysis}

For tissue western blots, mean target band densities for probe and PBBI groups are presented as a percent of the sham control value (100\%) calculated from individual membranes. For CSF western blots, target bands at each time point were normalized to the mean value of a positive control band generated from frontal cortex tissue lysates collected $24 \mathrm{~h}$ post-PBBI. Since variable volumes of CSF were used to concentrate proteins, these normalized band values were subsequently normalized by the original $\mu \mathrm{L}$ of CSF loaded for protein concentration. Concentrations of GFAP $(\mathrm{ng} / \mathrm{mL})$ obtained in ELISA experiments were also normalized by the original $\mu \mathrm{L}$ of CSF. For CSF western blots and ELISAs, any negative values that were generated (i.e., band signal equal to less than the calculated background signal or sample signal less than blank) were set as ' 0 ' for the purpose of data analysis. Sample sizes are detailed in the figure legends. Please note that 9-10 rats/group and time point were initiated on study, however, due to inability to collect CSF or insufficient collection volumes from all subjects, additional rats were injured for acute collections time points when necessary. All values are presented as mean \pm SEM. Outliers as determined by ROUT analysis $(Q=0.1 \%)$ were excluded from all data sets. For neuroscore, western blotting experiments, and ELISAs, significant injury 
effects were determined at each time point using a one-way ANOVA followed by Tukey's multiple comparisons test to compare experimental groups. Two-tailed Pearson correlation coefficients $(r)$ were determined using all available data points from Western blot experiments with sham, probe, and PBBI rats. For all analyses, results were considered statistically significant when $p<0.05$. All statistical analyses were performed using GraphPad Prism v6 (La Jolla, CA, United States).

\section{RESULTS}

\section{Neurological Impairment}

To evaluate neurological deficits following the probe injury and PBBI, neuroscore values were assessed at $24 \mathrm{~h}$ after injury compared to sham control procedures for all cohorts. Both probe injury $(3.38 \pm 0.42$, range $0-12)$ and PBBI $(6.75 \pm 0.31$, range $1.5-12)$ resulted in significantly elevated cumulative neuroscore values compared to sham $(0.43 \pm 0.10$, range 0-1.5) (Figure 1), indicating that both injuries result in acute neurological impairment. Additionally, PBBI animals had significantly elevated neuroscore values over probe-injured rats.

\section{Quantitation of GFAP, $\alpha$ Il-spectrin, and Calpain-II in Brain Tissues}

To determine the abundance of both full length GFAP (GFAP-FL) at $50 \mathrm{kDa}$ and its breakdown products (BDPs) from 37 to $48 \mathrm{kDa}$, the brain regions that directly encompass the injury trajectory (frontal cortex, striatum) and adjacent distal regions (hippocampus, residual midbrain) were examined by western blotting at $24 \mathrm{~h}, 3$ days, 7 days, 1 month, and 3 months following injury (Figure 2A). Quantitative analysis indicated that GFAPFL and GFAP-BDPs were elevated over time in both the probe injury and PBBI groups compared to sham. Probe injury alone resulted in significantly increased GFAP-FL in the brain regions which encompass the injury trajectory starting at 3 days (frontal cortex: peak of $589 \%$ at 7 days; striatum: peak of $397 \%$ at 7 days) (Figure 2B). This elevation was sustained through 3 months

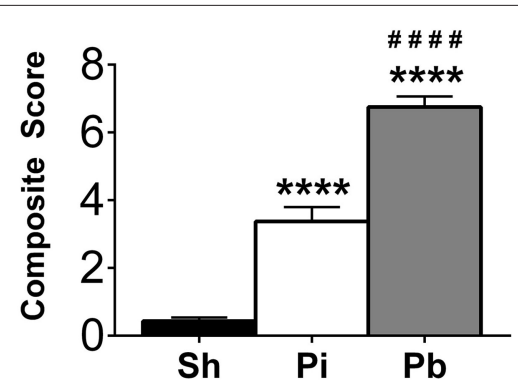

FIGURE 1 | Penetrating brain injury results in significant acute neurological deficits. Neuroscore evaluations were performed $24 \mathrm{~h}$ following injury in Sham (Sh, black bar), Probe Injury (Pi, white bar), and PBBI (Pb, gray bar) groups. Composite values are presented here from each injury condition regardless of the tissue collection time point. $N=44-50$ per group. ${ }^{* * * *} p \leq 0.0001 \mathrm{Pi}$ or $\mathrm{Pb}$ vs. Sh; \#\#\#\# $p \leq 0.0001 \mathrm{~Pb}$ vs. Pi, one-way ANOVA with Tukey's multiple comparisons test. in the frontal cortex. PBBI resulted in a slight, but significant, increase in GFAP-FL in the striatum starting at $24 \mathrm{~h}$. Beginning at 3 days, GFAP-FL was significantly increased following PBBI in all brain regions and persisted in the frontal cortex (peak of $995 \%$ at 7 days), striatum (peak of $912 \%$ at 1 month), and residual midbrain (peak of $276 \%$ at 1 month) through 3 months, whereas increases in the hippocampus (peak of $276 \%$ at 3 days) were resolved by 1 month.

As with GFAP-FL, significant elevations of GFAP-BDPs following probe injury compared to sham were detected only in the frontal cortex and striatum at 3 days (3247\%) or 7 days $(11,123 \%)$, respectively (Figure 2 C). In contrast, PBBI robustly increased GFAP-BPDs at all time points in the frontal cortex (peak of $25,450 \%$ at 7 days), striatum (peak of $38,230 \%$ at 7 days), and residual midbrain regions (peak of 525\% at 1 month). PBBI significantly increased GFAP-BDPs in the hippocampus at 3 days (1026\%) and 7 days (485\%). The consequence of increased injury severity on GFAP-FL and GFAP-BDPs was also determined by evaluating differential protein abundance between probe and PBBI injured rats. The abundance of GFAP-FL and GFAP-BDPs following PBBI was significantly increased over probe injury in a number of brain regions and time points assessed (Figures 2B,C), although this observation was less frequent than comparisons with sham.

Next, the abundance of $\alpha$ II-spectrin and spectrin breakdown products (SBDPs) was assayed in the same manner as GFAP. Visual inspection of the western blots confirmed that full length $\alpha \mathrm{II}$-spectrin was detectable at $280 \mathrm{kDa}$ as expected. After probe injury and PBBI, SBDP-145/150 was robustly evident, while SBDP-120 was minimally detected and poorly resolved (Figure 3A). Quantitative analysis revealed that probe injury decreased $\alpha \mathrm{II}$-spectrin compared to sham at 1 month in the striatum only (-24\%) (Figure 3B). PBBI acutely reduced $\alpha$ IIspectrin in the areas of the immediate injury trajectory (frontal cortex: maximum decrease of $-64 \%$ at 3 days, striatum: $-26 \%$ at $24 \mathrm{~h}$ only) compared to sham. In distal injury areas, no acute reductions in $\alpha \mathrm{II}$-spectrin were observed compared to sham. However, PBBI lowered $\alpha$ II-spectrin levels at subacute and chronic time points (hippocampus: $-57 \%$ at 3 month only, residual midbrain: maximum decrease of $-72 \%$ at 7 days).

Concomitant increases in SBDP-145/150 were also observed (Figure 3C). Probe injury increased SBDP-145/150 in the frontal cortex at $24 \mathrm{~h}$ and 3 days (peak of $1091 \%$ at $24 \mathrm{~h}$ ). Following PBBI, SBDP-145/150 increased starting at $24 \mathrm{~h}$ and remained elevated through 7 days in the frontal cortex (peak of $1742 \%$ at $24 \mathrm{~h}$ ), striatum (peak of $1731 \%$ at 3 days), and residual midbrain (peak of $1230 \%$ at 7 days). Levels detected in the striatum remained elevated until 1 month. In the hippocampus, PBBI led SBDP$145 / 150$ to increase at 3 days, only (182\%). Quantitative analysis of SBDP-120 revealed that this fragment was elevated, albeit at a much smaller magnitude than observed with SBDP-145/150 (Supplementary Figure S1). Probe injury increased SBDP-120 at 3 month in the frontal cortex only (262\%). PBBI resulted in significantly increased SBDP-120 in the frontal cortex at $24 \mathrm{~h}$ and 3 days (peak of $357 \%$ at $24 \mathrm{~h}$ ) and delayed increases in the hippocampus at 3 months (434\%) and the residual midbrain at 7 days and 1 month (peak of $349 \%$ at 1 month). Additionally, 


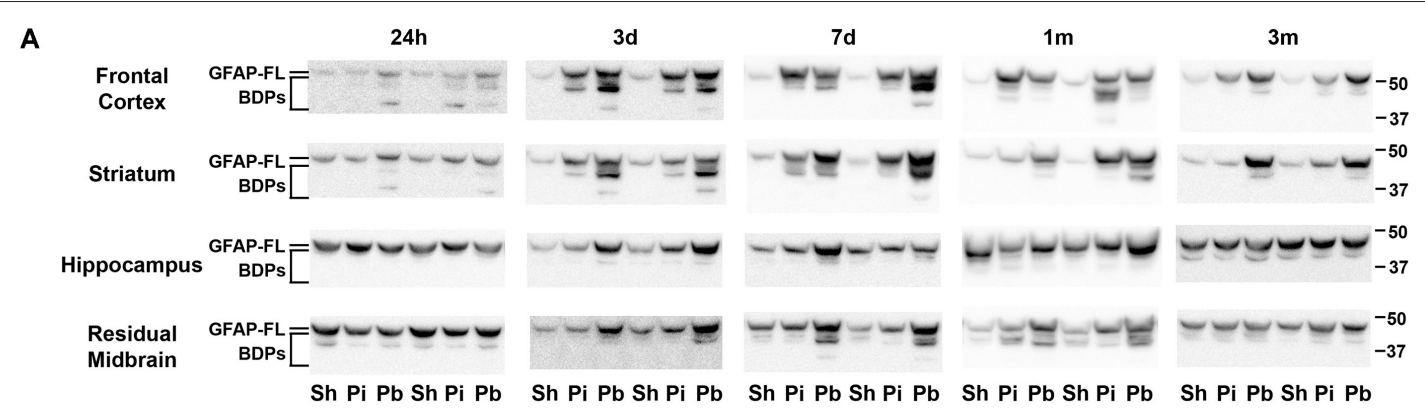

B
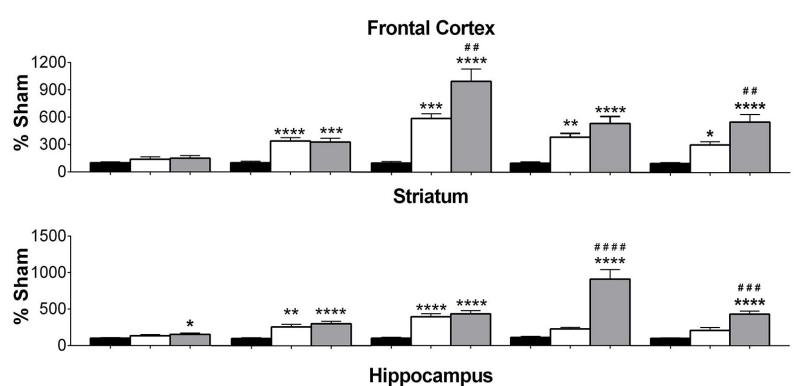

Hippocampus
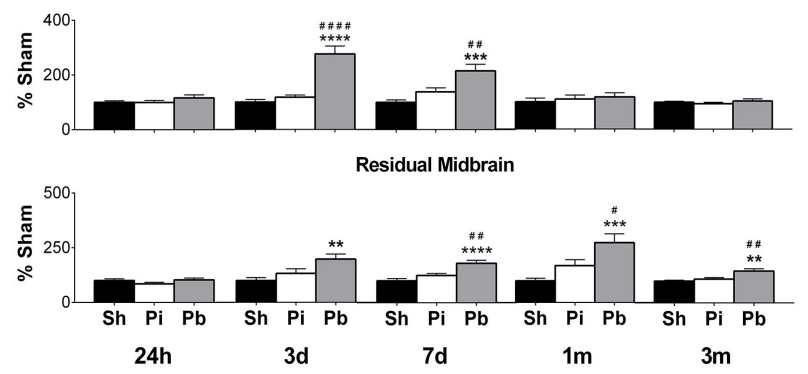

C
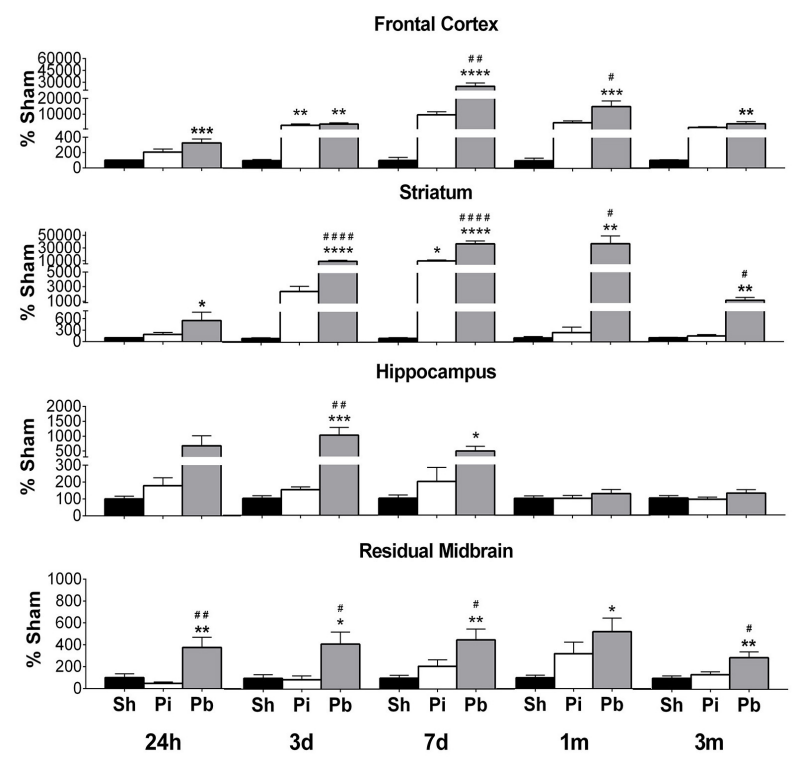

FIGURE 2 | Penetrating brain injury results in robust longitudinal increases in GFAP and GFAP-BDPs in brain tissue. (A) Representative western blots to illustrate GFAP and its BDPs at 24 h, 3 days, 7 days, 1 month, and 3 months post injury or sham manipulation in the frontal cortex, striatum, hippocampus, and residual midbrain areas. Full length GFAP (GFAP-FL) was detected as indicated at $50 \mathrm{kDa}$, with breakdown products ranging from 37 to $48 \mathrm{kDa}$. Depicted gels were loaded in the order of Sham (Sh), Probe (Pi), PBBI (Pb) as indicated. Quantitation of (B) GFAP-FL at 50 kDa and (C) GFAP-BDPs at $37-48$ kDa is presented as percent change from sham for each time point and brain region examined. Values are presented as mean $\pm \mathrm{SEM}$ for $\mathrm{Sh}$ (black bars), Pi (white bars), or Pb (gray bars) groups. $N=9-$

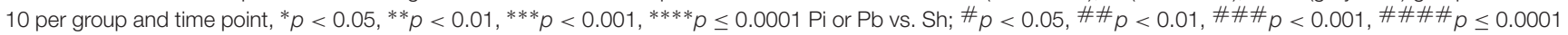
$\mathrm{Pb}$ vs. Pi, one-way ANOVA with Tukey's multiple comparisons test. Full blot images are available in Supplementary Figures S3-S6.

PBBI altered levels of $\alpha$ II-spectrin, SBDP-145/150, and SBDP-120 compared to probe insertion alone.

To determine if calpain-II was differentially abundant after brain trauma, protein levels were assessed by western blot in the cohorts used to define GFAP, $\alpha$ II-spectrin, and respective BDP levels (Figure 4). Prominent bands corresponding to fulllength calpain-II were detected at $73 \mathrm{kDa}$ (Figure 4A). Compared to sham, probe injury reduced calpain-II abundance in the frontal cortex $(-34 \%$ at 3 days) and the hippocampus $(-51 \%$ at 7 days) (Figure 4B). PBBI acutely reduced calpain-II abundance in the frontal cortex (maximum decrease of $-44 \%$ at 3 days), striatum (maximum decrease of $-34 \%$ at $24 \mathrm{~h}$ ), and residual midbrain (maximum decrease of $-30 \%$ at 3 days) compared to sham. Surprisingly, at 7 days after PBBI, increased calpain-II was observed in the frontal cortex and striatum (150 and 142\% respectively) compared to both sham and probe-injured rats.

\section{Detection of GFAP, GFAP-BDPs and SBDPs in CSF}

Cerebral spinal fluid samples were used to determine the abundance of GFAP, $\alpha$ II-spectrin, and their BDPs after injury. Total GFAP ELISAs (representing both GFAP-FL and GFAP-BDPs) indicated that neither probe nor PBBI resulted in significantly altered total GFAP at $24 \mathrm{~h}$ or 3 days after injury (Figure 5A). Total GFAP in CSF collected 7 days through 3 months was not readily detectable (data not shown). To discern if either GFAP-FL or GFAP-BDPs, rather than total GFAP, may change significantly as a result of injury in these samples, western blots were performed (Figure 5B). Visual inspection revealed the presence of GFAP-FL and the characteristic banding pattern for GFAP-BDPs at $24 \mathrm{~h}$ and 3 days. Quantitation of this data revealed no significant alteration in GFAP-FL and GFAP-BDPs as determined by western blot (Supplementary Figure S2). As 

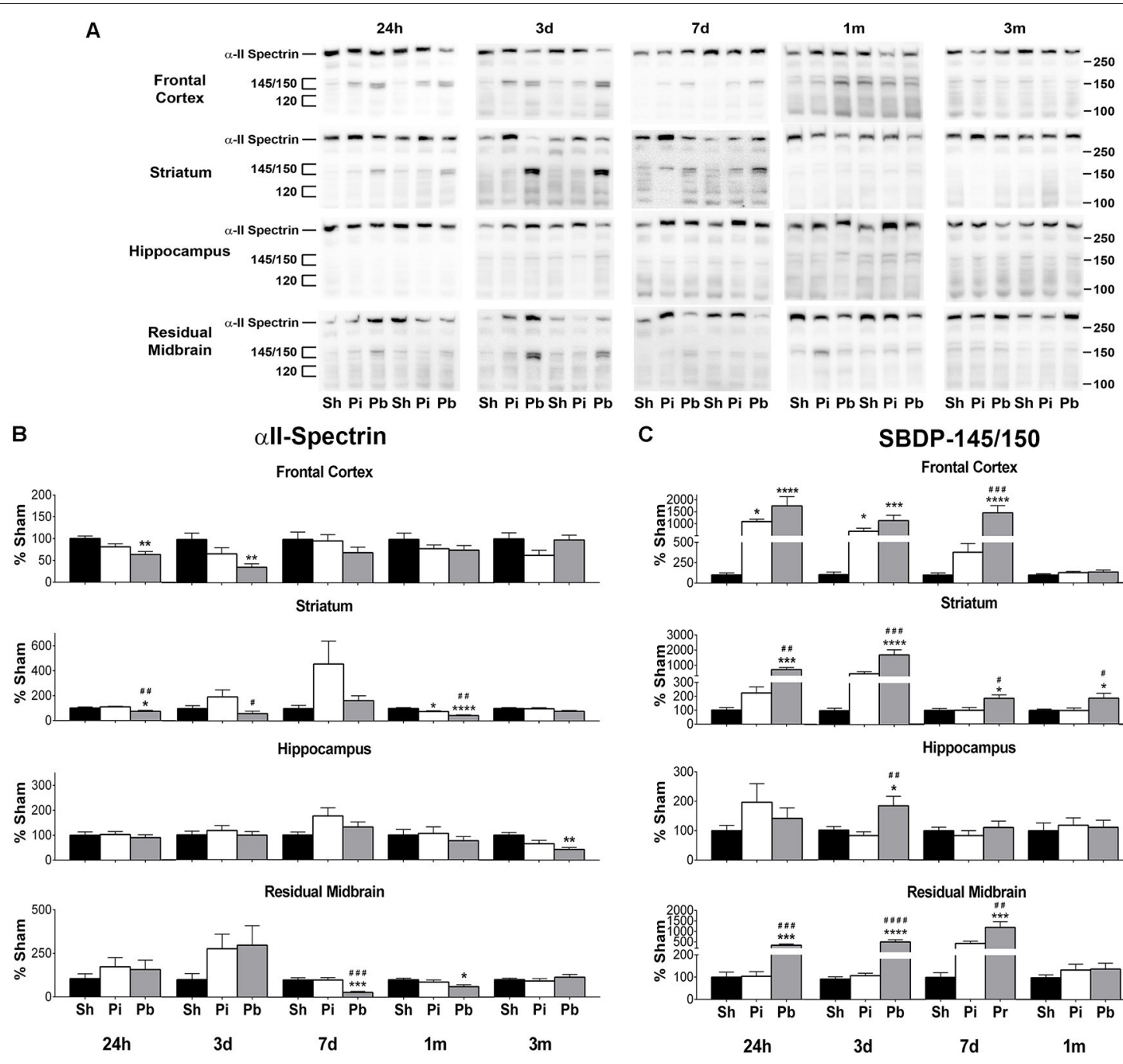

C

SBDP-145/150
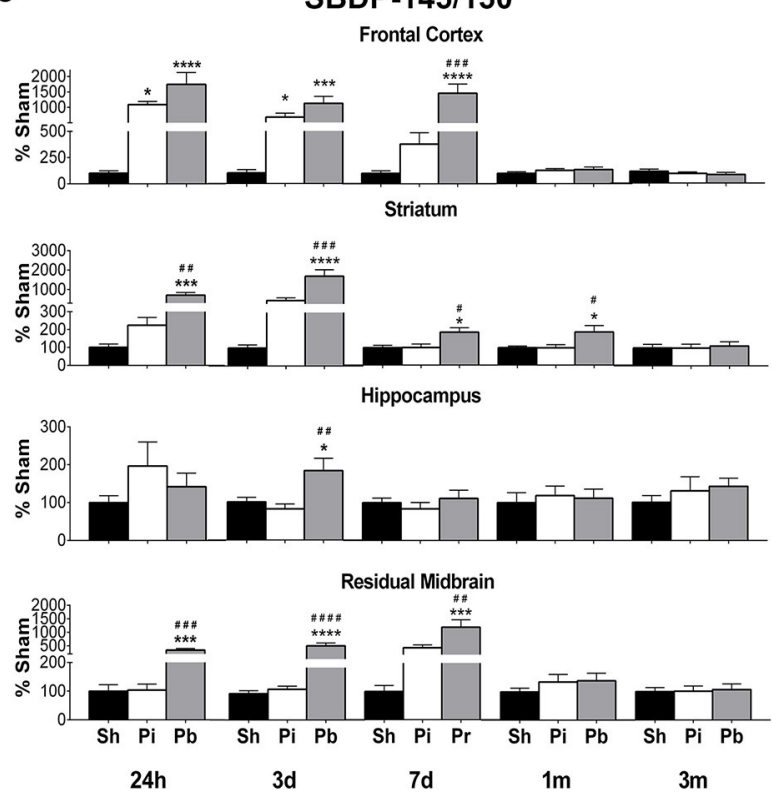

FIGURE 3 | Penetrating brain injury reduces the abundance of $\alpha$ ll-spectrin with concomitant increases in SBDP in brain tissues. (A) Representative western blots to illustrate all-spectrin and SBDP at $24 \mathrm{~h}, 3$ days, 7 days, 1 month, and 3 months post injury or sham manipulation in the frontal cortex, striatum, hippocampus, or residual midbrain regions. Alpha-II-spectrin was detected as indicated at $280 \mathrm{kDa}$, with SBDPs present at approximately $145 / 150$ and $120 \mathrm{kDa}$. Depicted gels were loaded in the order of Sham (Sh), Probe (Pi), PBBI (Pb) as indicated. Quantitation of (B) all-spectrin and (C) SBDP-145/150 is presented here as percent change from sham for each time point and brain region examined. Quantitation of SBDP-120 is available in Supplementary Figure S1. Values are presented as mean \pm SEM for Sh (black bars), $\mathrm{Pi}$ (white bars), or $\mathrm{Pb}$ (gray bars) groups. $\mathrm{N}=9-10$ per group and time point, ${ }^{*} p<0.05,{ }^{* *} p<0.01,{ }^{* * *} p<0.001,{ }^{* * * *} p \leq 0.0001 \mathrm{Pi}$ or $\mathrm{Pb}$ vs. Sh; $\# p<0.05, \# \# p<0.01, \# \# \# p<0.001$, \#\#\#\#p $\leq 0.0001 \mathrm{~Pb}$ vs. Pi, one-way ANOVA with Tukey's multiple comparisons test. Full blot images are available in Supplementary Figures S7-S10.

with ELISA analysis, levels in most samples were not readily detectable (data not shown) although GFAP-FL and GFAP-BDPs were evident in certain animals from 7 days to 3 month time points. Interestingly, GFAP-BDPs were detectable in a limited number of sham animals at acute through chronic times after injury.

Western blotting of CSF indicated that $\alpha$ II-spectrin, SBDP$145 / 150$, and SBDP-120 were present as late as 3 months after injury (Figure 6A). Quantitative analysis demonstrated that while probe injury did not alter $\alpha$ II-spectrin or SBDP levels, PBBI resulted in significant elevation of these analytes compared to both sham and probe injured groups (Figure 6B). Alpha II-spectrin was increased to 352 and $967 \%$ at $24 \mathrm{~h}$ and
3 days, respectively, while SBDP-145/150 was elevated by 2248 , $84,068 \%$, and by $649 \%$ at 24 h, 3 days, and 7 days post-PBBI, respectively. SBDP-120 rose by $1035 \%$ at 3 days.

\section{Correlations With Protein Levels in Brain Tissue Regions}

To determine if CSF levels of GFAP, $\alpha$ II-spectrin, and their BDPs may have utility to predict abundance of the same protein levels in brain tissues, correlation analyses were performed using grouped data points from all three conditions as described in materials and methods. These correlations between specific protein levels in CSF and the corresponding protein levels in brain tissues were performed for each brain region and time 

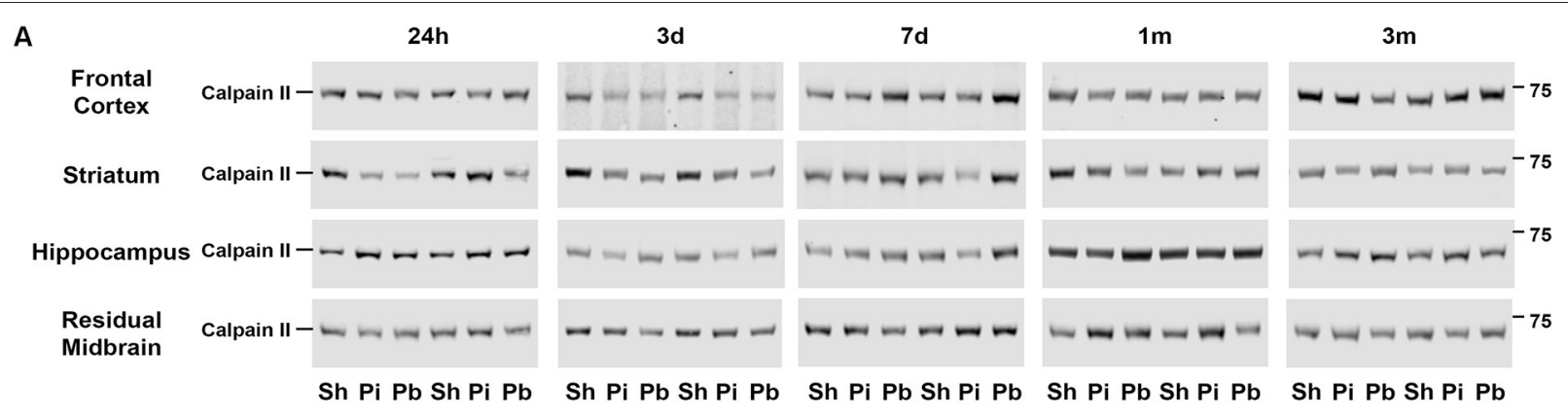

B
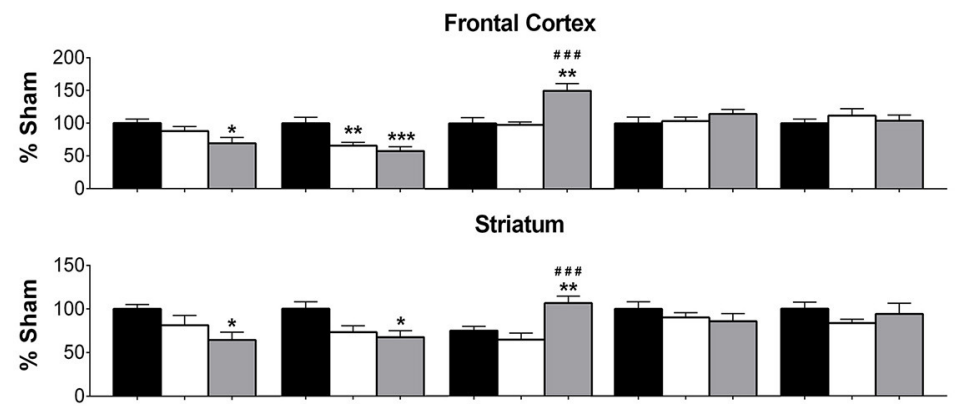

Hippocampus
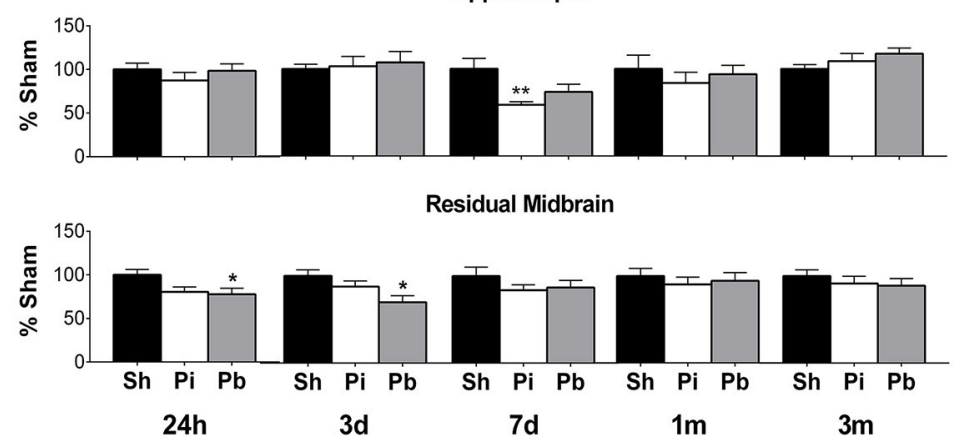

FIGURE 4 | Penetrating brain injury alters the abundance of full length calpain-II in brain tissues. (A) Representative western blots to illustrate full length calpain-II at 24 h, 3 days, 7 days, 1 month, and 3 months post injury or sham manipulation in the frontal cortex, striatum, hippocampus, or residual midbrain. Full length calpain- II was detected at approximately $72 \mathrm{kDa}$. Depicted gels were loaded in the order of Sham (Sh), Probe (Pi), PBBI (Pb) as indicated. (B) Quantitation of calpain-II is presented as percent change from sham for each time point and brain region examined. Values are presented as mean $\pm \mathrm{SEM}$ for Sh (black bars), Pi (white bars), or $\mathrm{Pb}$ (gray bars). $\mathrm{N}=9-10$ per group and time point, ${ }^{*} p<0.05,{ }^{*} p<0.01,{ }^{* * *} p<0.001 \mathrm{Pi}$ or Pb vs. Sh; \#\#\# $p<0.001 \mathrm{~Pb}$ vs. Pi, one-way ANOVA with Tukey's multiple comparisons test. Full blot images are available in Supplementary Figures S11-S14.

point. GFAP-BDPs, but not GFAP-FL, revealed many significant positive correlations between CSF and tissues (Supplementary Table S1). GFAP-FL in CSF correlated with levels detected in the hippocampus at 3 days alone $(r=0.579)$. Starting at $24 \mathrm{~h}$, GFAP-BDPs in CSF correlated with these same cleavage products in the frontal cortex, striatum, and residual midbrain ( $r$ range: from 0.476 to 0.569 ). This observation persisted at 3 days with the frontal cortex, striatum, and hippocampus ( $r$ range: $0.511-0.797$ ). Similar to the results for GFAP, the relationship between SBDP, but not $\alpha$ II-spectrin, in CSF and brain tissues was significant in many instances (Table 1). This result was overwhelmingly true for SBDP$145 / 150$ where significant correlations between CSF and brain tissue abundance were observed at $24 \mathrm{~h}$ in the striatum and residual midbrain ( $r=0.582$ and 0.655 , respectively) and at $3 \mathrm{~d}$ in the striatum, hippocampus, and residual midbrain ( $r$ range: $0.498-0.918$ ). This correlation persisted at 7 days in the frontal cortex, striatum, and residual midbrain areas $(r$ range: $0.507-0.777)$. CSF SBDP-120 was positively associated with values detected in the frontal cortex at 7 days post injury only $(r=0.560)$.

Additional correlations were performed to determine the relationship between acute neurological deficits and brain tissue protein abundance grouped from all three injury conditions. Overall, acute neuroscore values were positively associated with GFAP-FL and GFAP-BDPs in brain (Table 2). At 3 days ( $r$ range: $0.498-0.749$ ) and 7 days (0.476-0.828), GFAP-FL and GFAP-BDP abundance in all brain regions correlated 


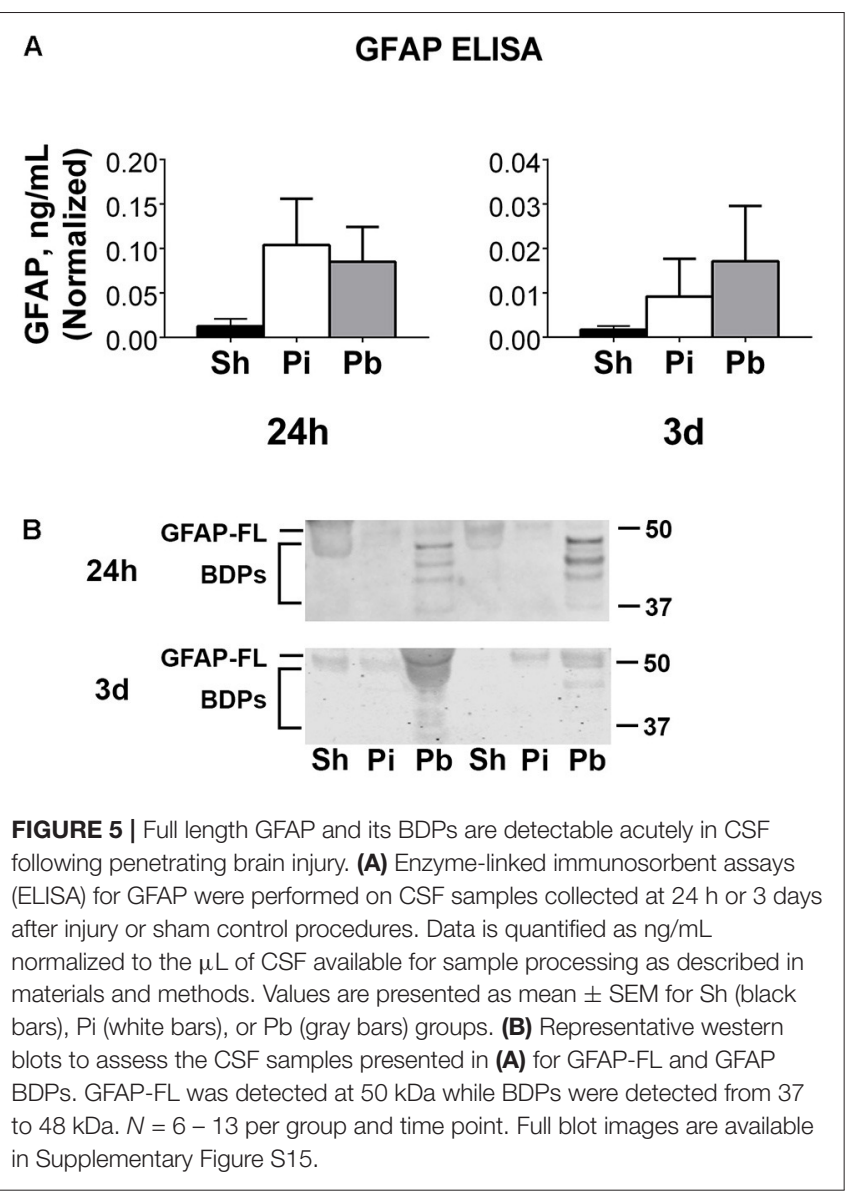

significantly with neurological deficits. Acute neuroscore values and brain $\alpha$ II-spectrin levels were negatively associated with one another throughout acute-chronic injury (Table 3). This negative association was strongest at 7 days $(r=-0.632$ in residual midbrain). In accordance with the gain of SBDPs in brain tissues, analysis indicated that these levels were positively associated with acute neurological deficits. This was overwhelmingly true of SBDP-145/150 detected at 24 h-7 days, wherein this correlation was significant among all four brain regions at 3 days, but was greatest with the residual midbrain $(r=0.742)$. Fewer instances of significance were observed with analysis of SBDP-120 levels, where the strongest correlation was with the residual midbrain at 7 days $(r=0.664)$.

\section{DISCUSSION}

This study provides a comprehensive evaluation of welldescribed TBI biomarkers (GFAP, $\alpha$ II-spectrin, and their BDPs) in brain tissue regions and CSF throughout acute-chronic (24 h to 3 months) injury progression. A representation of this timeline following PBBI is indicated for brain tissues (Figure 7A) as approximated from the immediate areas of the primary injury trajectory (frontal cortex and striatum) and CSF (Figure 7B). PBBI resulted in widespread time-dependent changes in protein abundance, which was especially robust for BDPs as opposed to intact, full-length counterparts within several brain regions. While effects were also evident to some degree in animals exposed to insertion of the probe alone, the majority of injury effects appear to result from the ballistic-like force of the injury captured by the rapid inflation/deflation of the balloon inside the rat brain. This study indicated that CSF SBDP-145/150 levels may have utility during acute-subacute injury to serve as an indicator of neuronal degradation in the brain. Further, this study indicated that acute neurological deficits were associated with levels of GFAP, $\alpha I I$-spectrin, and BDPs as late as 3 months after injury.

\section{Temporal Progression of Astroglial and Neuronal BDPs}

GFAP and $\alpha$ II-spectrin proteolysis and subsequent BDP generation in brain tissue is well-established following TBI but has focused on the acute time frame (24-27). This study indicates that GFAP and $\alpha$ II-spectrin degradation, and the resulting increased generation of BDPs, is progressive and dominant during subacute-chronic time frames. The increase in GFAPBDPs and SBDPs after both probe injury and PBBI provide evidence that both GFAP-FL in astrocytes and $\alpha \mathrm{II}$-spectrin in neurons undergo long-term proteolysis as a consequence of PBBI, albeit with distinct temporal profiles. These diverging profiles indicate that reactive astrogliosis (GFAP-FL) and astroglial protein degradation (GFAP-BDP) are comparatively delayed following $\mathrm{PBBI}$ and persist chronically. In contrast, neuronal cytoskeletal protein degradation (SBDP-145/150) is prominent within acute-subacute time frames but resolves afterward, which is likely due to the resolution of the core lesion into an intracranial cavity by 7 days following PBBI (38). This pattern may extend to other injury models as well, since acute elevation of SBDP within 7-14 days (39) and chronic upregulation of GFAP up to 1 year $(40,41)$ have been previously reported. These distinct temporal profiles associated with GFAP and aII-spectrin inform the duration of drug treatment paradigms targeted toward specific mechanisms, such as the chronic sustainment of astrogliosis and proteolysis of GFAP-FL into GFAP-BDPs.

Calpain- or caspase- mediated protein degradation is proposed to be a key factor in TBI mediated neurodegeneration. Generation of GFAP-BDPs and SBDP-145/150 are products of calpain-mediated proteolysis (26), whereas proteolysis by caspase-3 activity results primarily in generation of SBDP-120 (42). The results presented here indicate the predominance of calpain-mediated cleavage products in the acute-chronic periods following PBBI. Additionally, this study demonstrated an overall loss in full length calpain-II, an indirect marker of calpain activation (43), following PBBI within brain regions that were proximal as well as somewhat distal to the injury tract. Calpain-II is decreased during truncation and activation prior to degradation of protein substrates (42), however, calpain-II fragments that represent the active form of the enzyme were not detectable in this study. As a minor point, full-length calpainII increased 7 days after PBBI, a finding that has previously been reported in a blast model of TBI (44) and may reflect a 
A

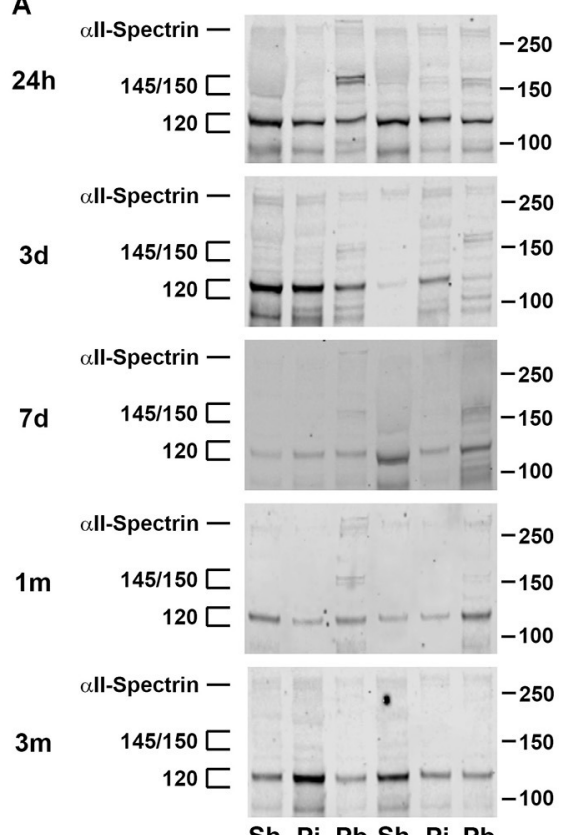

B

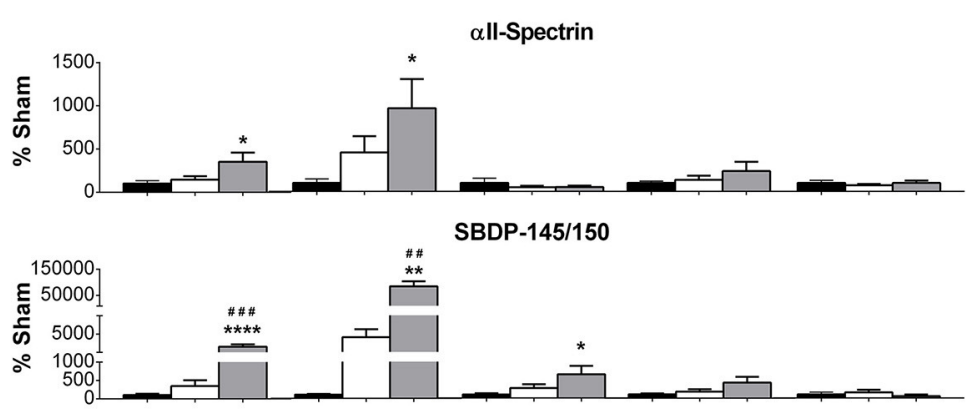

SBDP-120

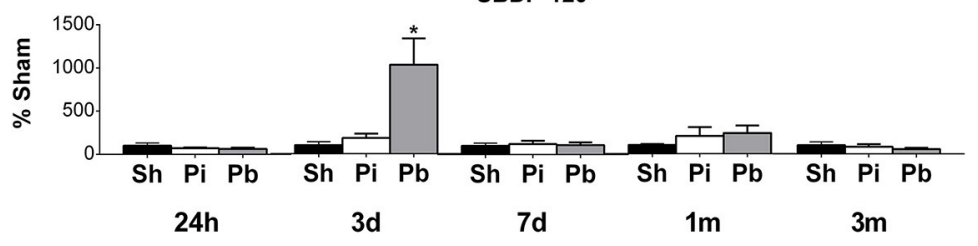

FIGURE 6 | Alpha-II-spectrin and SBDP-145/150 and SBDP-120 are detectable longitudinally in CSF following penetrating brain injury. (A) Representative western blots in CSF collected at $24 \mathrm{~h}, 3$ days, 7 days, 1 month, and 3 months after injury or sham control manipulations. Alpha-II-spectrin was detected at $280 \mathrm{kDa}$ while SBDPs were detected at 145/150 and $120 \mathrm{kDa}$. Gels were loaded in the order of Sham (Sh), Probe (Pi), PBBI (Pb) as indicated. (B) Quantitation of all-spectrin and SBDPs at the indicated molecular weights is presented here as band density normalized to original $\mu \mathrm{L}$ of CSF available for sample processing as described in materials and methods. Values are presented as mean \pm SEM for Sh (black bars), Pi (white bars), or Pb (gray bars) groups. $N=7-13$ per group and time point,

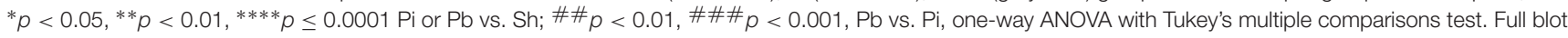
images are available in Supplementary Figure S16.

TABLE 1 | Correlation results between full length all-spectrin or SBDP protein levels in CSF and tissues specified by brain region and time point.

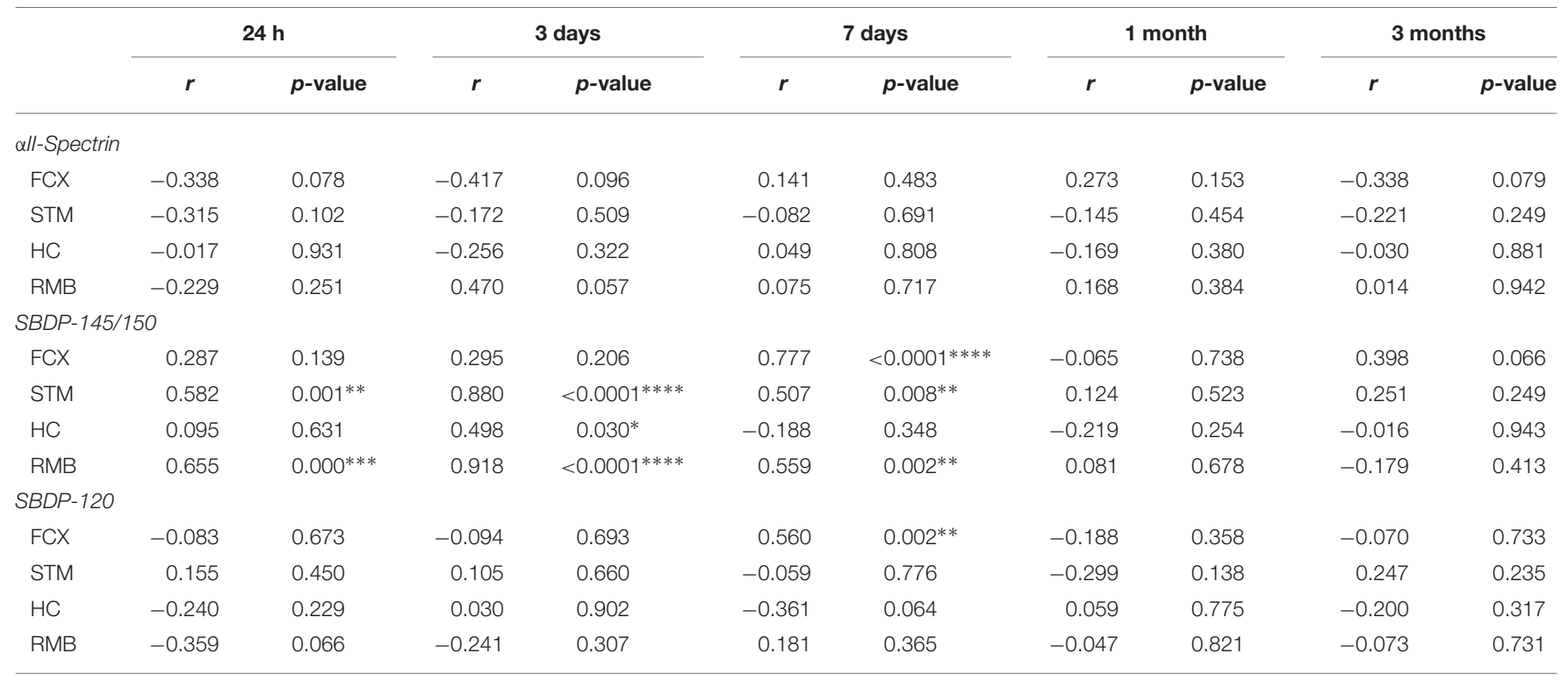

Pearson r correlation analyses were performed between levels of all-spectrin or SBDPs in CSF and brain tissues by region and time point post injury. Protein levels were determined by Western blot at each time point post injury and were expressed as normalized values for CSF markers and as a percent sham for tissue markers for analysis. Sham, Probe, and PBBI injured rats were all included for analysis. Significant correlations are marked with $*(p<0.05)$, ${ }^{* *}(p<0.01),{ }^{* * *}(p<0.001)$, or $* * * *(p \leq 0.0001)$. CSF, cerebrospinal fluid; FCX, frontal cortex; STM, striatum; HC, hippocampus; RMB, residual midbrain. 
TABLE 2 | Correlation results between GFAP-FL and GFAP-BDP protein tissue levels and neuroscore values specified by brain region and time point.

\begin{tabular}{|c|c|c|c|c|c|c|c|c|c|c|}
\hline & \multicolumn{2}{|c|}{$24 \mathrm{~h}$} & \multicolumn{2}{|c|}{3 days } & \multicolumn{2}{|c|}{7 days } & \multicolumn{2}{|c|}{1 month } & \multicolumn{2}{|c|}{3 months } \\
\hline & $r$ & $p$-value & $r$ & $p$-value & $r$ & $p$-value & $r$ & $p$-value & $r$ & $p$-value \\
\hline \multicolumn{11}{|c|}{ GFAP-FL } \\
\hline FCX & 0.293 & 0.116 & 0.498 & $0.005^{* *}$ & 0.749 & $<0.0001^{* * * *}$ & 0.587 & $0.007 * *$ & 0.392 & $0.036^{*}$ \\
\hline STM & 0.482 & $0.007^{* *}$ & 0.521 & $0.003^{* *}$ & 0.559 & $0.002^{* *}$ & 0.677 & $0.002^{* *}$ & 0.361 & 0.054 \\
\hline $\mathrm{HC}$ & 0.243 & 0.196 & 0.731 & $<0.0001 * * * *$ & 0.647 & $0.000 * * *$ & -0.001 & 0.995 & 0.109 & 0.573 \\
\hline $\mathrm{RMB}$ & 0.104 & 0.586 & 0.695 & $<0.0001^{* * * *}$ & 0.665 & $<0.0001^{* * * *}$ & 0.601 & $0.005^{* *}$ & 0.250 & 0.190 \\
\hline \multicolumn{11}{|c|}{ GFAP-BDPS } \\
\hline FCX & 0.655 & $<0.0001^{* * * *}$ & 0.528 & $0.003^{* *}$ & 0.800 & $<0.0001^{* * * *}$ & 0.431 & 0.074 & 0.272 & 0.162 \\
\hline STM & 0.630 & $0.000 * * *$ & 0.698 & $<0.0001^{* * * * *}$ & 0.828 & $<0.0001^{* * * * *}$ & 0.467 & $0.044^{*}$ & 0.357 & 0.058 \\
\hline $\mathrm{HC}$ & 0.264 & 0.202 & 0.476 & $0.010 *$ & 0.404 & $0.027^{*}$ & 0.105 & 0.659 & 0.236 & 0.217 \\
\hline $\mathrm{RMB}$ & 0.427 & $0.021^{*}$ & 0.701 & $<0.0001^{* * * *}$ & 0.594 & $0.001^{* * *}$ & 0.553 & $0.012^{*}$ & 0.424 & $0.024^{*}$ \\
\hline
\end{tabular}

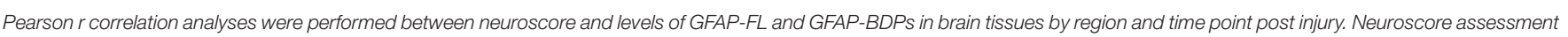

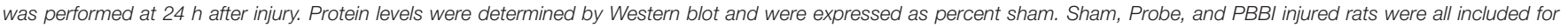

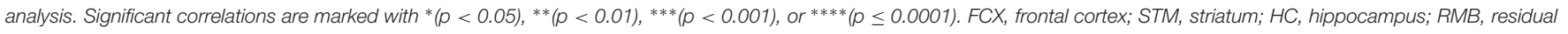
midbrain.

TABLE 3 | Correlation results between $\alpha$ ll-spectrin and SBDP protein tissue levels and neuroscore values specified by brain region and time point.

\begin{tabular}{|c|c|c|c|c|c|c|c|c|c|c|}
\hline & \multicolumn{2}{|c|}{$24 \mathrm{~h}$} & \multicolumn{2}{|c|}{3 days } & \multicolumn{2}{|c|}{7 days } & \multicolumn{2}{|c|}{1 month } & \multicolumn{2}{|c|}{3 months } \\
\hline & $r$ & $p$-value & $r$ & $p$-value & $r$ & $p$-value & $r$ & $p$-value & $r$ & $p$-value \\
\hline \multicolumn{11}{|c|}{$\alpha / l-S p e c t r i n$} \\
\hline FCX & -0.470 & $0.009 * *$ & -0.568 & $0.001^{* *}$ & -0.274 & 0.143 & -0.290 & 0.214 & -0.133 & 0.499 \\
\hline STM & -0.353 & 0.055 & -0.327 & 0.078 & -0.123 & 0.525 & -0.520 & $0.019 *$ & -0.095 & 0.623 \\
\hline $\mathrm{HC}$ & -0.041 & 0.831 & -0.169 & 0.374 & 0.159 & 0.401 & -0.058 & 0.807 & -0.465 & $0.013^{*}$ \\
\hline $\mathrm{RMB}$ & 0.160 & 0.408 & 0.228 & 0.226 & -0.632 & $0.000^{* * *}$ & -0.412 & 0.071 & 0.431 & $0.020^{*}$ \\
\hline \multicolumn{11}{|c|}{ SBDP-145/150 } \\
\hline FCX & 0.681 & $<0.0001^{* * * * *}$ & 0.565 & $0.001 * *$ & 0.692 & $<0.0001^{* * * *}$ & 0.136 & 0.567 & -0.243 & 0.213 \\
\hline STM & 0.628 & $0.000^{* * *}$ & 0.590 & $0.001^{* * *}$ & 0.731 & $<0.0001^{* * * *}$ & 0.293 & 0.211 & -0.246 & 0.198 \\
\hline $\mathrm{HC}$ & 0.039 & 0.837 & 0.434 & $0.019 *$ & 0.123 & 0.518 & 0.266 & 0.257 & 0.499 & $0.007^{* *}$ \\
\hline $\mathrm{RMB}$ & 0.517 & $0.004^{* *}$ & 0.742 & $<0.0001^{* * * * *}$ & 0.715 & $<0.0001^{* * * *}$ & 0.554 & $0.011^{*}$ & 0.196 & 0.307 \\
\hline \multicolumn{11}{|c|}{ SBDP-120 } \\
\hline FCX & 0.410 & $0.025^{*}$ & 0.456 & $0.011^{*}$ & 0.249 & 0.184 & 0.146 & 0.540 & 0.115 & 0.560 \\
\hline STM & -0.134 & 0.497 & 0.037 & 0.844 & -0.086 & 0.658 & 0.133 & 0.575 & -0.351 & 0.073 \\
\hline $\mathrm{HC}$ & 0.208 & 0.278 & 0.054 & 0.776 & -0.125 & 0.511 & -0.090 & 0.713 & 0.347 & 0.065 \\
\hline $\mathrm{RMB}$ & 0.031 & 0.872 & -0.278 & 0.138 & 0.664 & $<0.0001^{* * * * *}$ & 0.267 & 0.255 & -0.273 & 0.169 \\
\hline
\end{tabular}

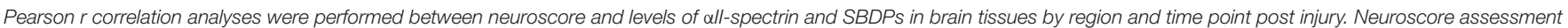

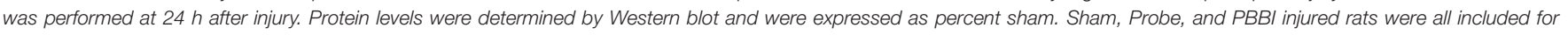

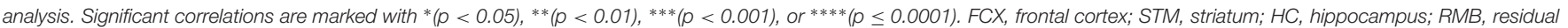
midbrain.

compensatory response to injury that has yet to be clearly defined based on TBI mechanism and/or severity.

\section{Variation Across Multiple Brain Regions}

This study indicates that chronic, progressive degradation occurs not only in brain regions containing the primary lesion as previously reported $(30,32,45)$ but also within areas that are adjacent to the primary wound, albeit with differing magnitudes. In this study, the effects of PBBI were not only more severe in the immediate regions of the primary injury trajectory (i.e., frontal cortex) as opposed to more distal areas (i.e., hippocampus), but also appeared more quickly and persisted for a longer duration. Interestingly, the temporal profiles of GFAP-FL and GFAPBDPs revealed that peak levels varied with time and between regions containing the primary injury lesion and distal injury areas. These divergent temporal profiles likely reflect a more rapid resolution of secondary injury effects in the less severely injured areas, whereas astrogliosis and proteolysis continue to increase progressively past 3 days before improving somewhat by 3 months in the more severely injured brain regions. Distinct profiles of protein abundance by brain region have been reported with SBDP-145/150 following CCI (39) and the data presented 


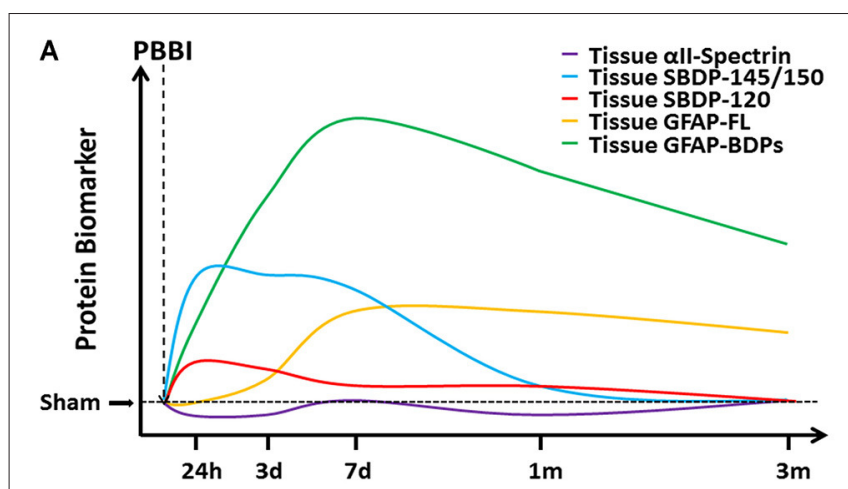

B

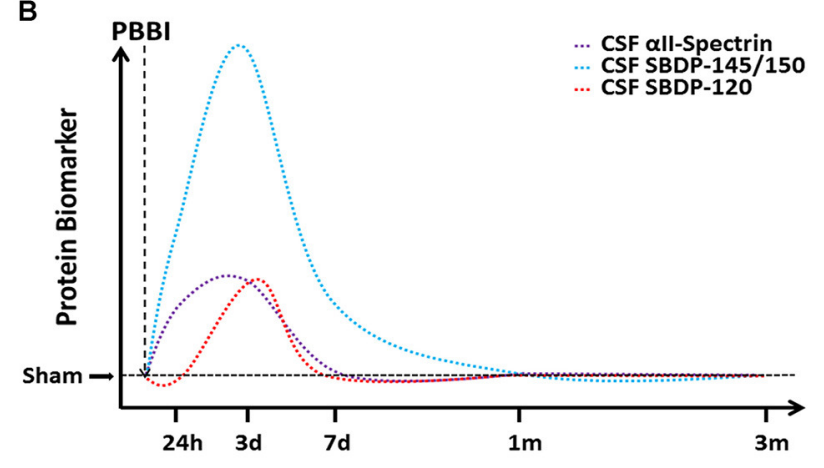

FIGURE 7 | A cartoon timeline of protein based biomarkers following PBBI. Changes in protein biomarker levels are presented here for $(\mathbf{A})$ tissue proteins and (B) CSF proteins as indicated, with increasing time on the $x$-axis and increasing protein abundance on the $y$-axis. Please note that axes are not drawn to scale and that these curves have been approximated from PBBI rats, with tissue curves representing changes in the brain regions of the immediate injury trajectory (frontal cortex and striatum).

here are consistent with previous work following PBBI showing delayed injury induced responses in the thalamus compared to the primary lesion (38).

This work corroborates and expands upon previous work from our laboratory, which defined the presence of GFAP, $\alpha$ IIspectrin, and their BDPs in a coronal brain section containing the primary injury lesion through 7 days after PBBI (27) with a few noteworthy exceptions. First, our previous data indicated that GFAP-FL abundance declines at 3 days after injury, which contrasts with the elevations observed in this study. Second, levels of $\alpha$ II-spectrin were nearly ablated by 3 days following PBBI previously, whereas here we see reductions of a smaller magnitude. Finally, significantly increased SBDP-145/150 were not seen previously at $24 \mathrm{~h}$ after PBBI as opposed to the robust increases in most brain regions assessed at this time-point in the current study. Whereas the first study isolated an ipsilateral coronal brain section combining both cortical and subcortical structures in each analysis, this study dissected specific ipsilateral brain regions with differing anatomical locations in relation to the primary injury trajectory. These data indicate that differential protein abundance of these tissue markers varies greatly between these distinct brain regions; thus, a greater resolution within each region of interest is likely to account for the differences observed here compared to our previous work. In addition, evaluating specific regions of interest provides useful information regarding regional injury progression as opposed to examination of a single brain section containing the primary injury lesion $(19,46)$.

\section{The Role of the Ballistic-Like Injury Component on Magnitude and Distribution of Neurodegeneration}

The differential effects of penetrating injury alone compared to a penetrating ballistic-like injury were examined here by inclusion of both the probe injury and PBBI groups, respectively. While both injuries resulted in acute neurological deficits compared to sham rats, these deficits were of a greater magnitude following PBBI compared to probe injury. Greater elevation in the tissue abundance of GFAP, $\alpha$ II-spectrin, and their BDPs in PBBI compared to probe injured rats was also observed longitudinally across multiple brain regions. This is consistent with previous work that has indicated elevated SBDP-145/150 following more severe CCI (47). These data provide both functional and molecular outcome measures to better distinguish how these different injuries may alter the progression of molecular pathology. For example, while significant changes in GFAP, $\alpha$ IIspectrin, and their BDPs following probe injury were observed, these instances were limited to the frontal cortex and striatum only with no evidence for the spread of this pathology to distal brain regions as seen following PBBI. This finding indicates that while probe insertion alone causes localized injury effects, the temporary cavity mimicking energy dissipation from a highvelocity bullet round plays a critical role in the severity of injury and the propagation of PBBI pathology to areas beyond the primary injury trajectory.

\section{Biofluid Based Biomarkers as Direct Correlates of Tissue Protein Abundance}

The identification and validation of biofluid based biomarkers for use in informing individualized treatment plans and/or monitoring the efficacy of treatment over time holds great potential for improving TBI patient outcomes. Both GFAP-BPDs (48) and SBDPs (49) have been reported in CSF samples taken from acute and subacute human TBI patients. These studies indicate that acute levels of CSF SBDP-145/150 are elevated in severe TBI patients who fare worse across multiple outcome metrics, including acute Glasgow Coma Scale and chronic Glasgow Outcome Scale scores. The results presented in this study suggest that SBDP-145/150, rather than GFAP, GFAPBDPs, or SBDP-120, may have utility as a monitoring biomarker through subacute-chronic stages following injury. Additionally, multiple correlations between CSF GFAP-BDPs and SBDP$145 / 150$ and tissue levels of these same proteins were significant. These data suggest that CSF levels of these BDPs may reflect their presence in brain tissues following injury. While some studies have assessed serum GFAP-BPDs specifically (50), others have evaluated a combination of both GFAP and GFAP-BDPs as biomarkers $(51,52)$. Our data demonstrated that CSF BDPs of GFAP and $\alpha I I$-spectrin, rather than their full length counterparts, 
were overwhelmingly correlated to these same protein forms in tissues, indicating that future studies evaluating the efficacy of CSF TBI biomarkers may benefit from measuring BDPs specifically. Whether these CSF biomarkers precede, co-occur, or follow injury-induced changes in these tissue proteins is unclear from our data. Interestingly, even in the absence of significant group effects, numerous significant correlations of acute and subacute levels of GFAP-BDPs and SBDP-145/150 between CSF and tissues were obtained, emphasizing the importance of these CSF biomarkers to predict molecular changes in individual subjects.

\section{Neurological Deficits as Predictors of Protein Degradation}

Acute neurological deficits correlated significantly with acutechronic brain tissue levels of GFAP, $\alpha$ II-spectrin, and BDPs, however, these associations presented in a different pattern than the CSF correlations discussed above. While significant CSF correlations resulted primarily from GFAP-BDPs and SBDP$145 / 150$, significant relationships between neuroscore values and brain tissue protein levels were more generalized and not as limited to BDPs specifically. This was especially true for GFAP. One explanation for this difference is that more severe injuries that cause greater neurological deficits are more likely to result in generalized injury induced alterations in protein abundance. Thus, in clinical practice, the assessment of neurological deficits with rating scales such as the NOS-TBI may have more benefit for classification of injury severity (53) and prediction of extended outcomes (54) rather than predictive ability for specific chronic neurodegeneration.

\section{CONCLUSION}

This study is the first to characterize acute through chronic profiles of the well-known TBI biomarkers GFAP, $\alpha$ II-spectrin, and their BDPs in distinct brain regions of interest, identify the presence of these proteins and their BDPs in CSF, and demonstrate significant correlations between the levels of BDPs present in CSF and brain tissues following PBBI in rats. These

\section{REFERENCES}

1. DVBIC. DoD Numbers for Traumatic Brain Injury: Defense and Veterans Brain Injury Center (2018). Available online at: http://dvbic.dcoe.mil/dodworldwide-numbers-tbi

2. Joseph B, Aziz H, Pandit V, Kulvatunyou N, O’Keeffe T, Wynne J, et al. Improving survival rates after civilian gunshot wounds to the brain. J Am Coll Surg. (2014) 218:58-65. doi: 10.1016/j.jamcollsurg.2013.08.018

3. Selassie AW, McCarthy ML, Ferguson PL, Tian J, Langlois JA. Risk of posthospitalization mortality among persons with traumatic brain injury, South Carolina 1999-2001. J Head Trauma Rehabil. (2005) 20:257-69. doi: 10.1097/00001199-200505000-00008

4. Harrison-Felix CL, Whiteneck GG, Jha A, DeVivo MJ, Hammond FM, Hart DM. Mortality over four decades after traumatic brain injury rehabilitation: a retrospective cohort study. Arch Phys Med Rehabil. (2009) 90:1506-13. doi: 10.1016/j.apmr.2009.03.015

5. Harrison-Felix C, Pretz C, Hammond FM, Cuthbert JP, Bell J, Corrigan J, et al. Life expectancy after inpatient rehabilitation for traumatic results indicate that a sustained period of reactive astrogliosis but finite period of axonal cytoskeletal degradation follow penetrating brain injury and that the detection of calpain generated BDPs in CSF may predict the underlying presence of these tissue proteins in real time. Additionally, the evidence for chronic proteolysis and astrogliosis presented in this study informs the design of drug treatment paradigms following penetrating TBI, indicating that prolonged treatments into subacute-chronic periods should be considered.

\section{DATA AVAILABILITY STATEMENT}

The raw data supporting the conclusions of this manuscript will be made available by the authors, without undue reservation, to any qualified researcher.

\section{AUTHOR CONTRIBUTIONS}

$\mathrm{KD}, \mathrm{CC}, \mathrm{AB}$, and $\mathrm{DS}$ designed the experiments and prepared the manuscript. $\mathrm{KD}, \mathrm{CC}$, and $\mathrm{HH}$ performed the experiments and conducted data analysis.

\section{FUNDING}

Portions of this work have previously been presented as posters at National Neurotrauma Symposia $(55,56)$. This research was funded by the U.S. Army Medical Research and Material Command's Combat Casualty Care Research Program.

\section{ACKNOWLEDGMENTS}

The authors thank Justin Hahn for technical expertise with sample collections.

\section{SUPPLEMENTARY MATERIAL}

The Supplementary Material for this article can be found online at: https://www.frontiersin.org/articles/10.3389/fneur. 2018.00490/full\#supplementary-material

brain injury in the United States. J Neurotrauma (2015) 32:1893-901. doi: $10.1089 /$ neu.2014.3353

6. Selassie AW, Zaloshnja E, Langlois JA, Miller T, Jones P, Steiner C. Incidence of long-term disability following traumatic brain injury hospitalization, United States, 2003. J Head Trauma Rehabil. (2008) 23:123-31. doi: 10.1097/01.HTR.0000314531.30401.39

7. Zaloshnja E, Miller T, Langlois JA, Selassie AW. Prevalence of longterm disability from traumatic brain injury in the civilian population of the United States, 2005. J Head Trauma Rehabil. (2008) 23:394-400. doi: 10.1097/01.HTR.0000341435.52004.ac

8. Masel BE, DeWitt DS. Traumatic brain injury: a disease process, not an event. J Neurotrauma (2010) 27:1529-40. doi: 10.1089/neu.2010.1358

9. Cooper DJ, Rosenfeld JV, Murray L, Arabi YM, Davies AR, D'Urso P, et al. Decompressive craniectomy in diffuse traumatic brain injury. $N$ Engl J Med. (2011) 364:1493-502. doi: 10.1056/NEJMoa 1102077

10. Hutchinson PJ, Kolias AG, Timofeev IS, Corteen EA, Czosnyka M, Timothy J, et al. Trial of decompressive craniectomy for traumatic 
intracranial hypertension. $N$ Engl $J$ Med. (2016) 375:1119-30. doi: 10.1056/NEJMoa1605215

11. Fineman I, Hovda DA, Smith M, Yoshino A, Becker DP. Concussive brain injury is associated with a prolonged accumulation of calcium: a 45Ca autoradiographic study. Brain Res. (1993) 624:94-102. doi: 10.1016/0006-8993(93)90064-T

12. Nilsson P, Hillered L, Olsson Y, Sheardown MJ, Hansen AJ. Regional changes in interstitial $\mathrm{K}^{+}$and $\mathrm{Ca}^{2+}$ levels following cortical compression contusion trauma in rats. J Cereb Blood Flow Metab. (1993) 13:183-92. doi: $10.1038 /$ jcbfm.1993.22

13. Nadler V, Biegon A, Beit-Yannai E, Adamchik J, Shohami E. $45 \mathrm{Ca}$ accumulation in rat brain after closed head injury; attenuation by the novel neuroprotective agent HU-211. Brain Res. (1995) 685:1-11. doi: 10.1016/0006-8993(95)00367-Y

14. Kampfl A, Posmantur R, Nixon R, Grynspan F, Zhao X, Liu SJ, et al. mu-calpain activation and calpain-mediated cytoskeletal proteolysis following traumatic brain injury. J Neurochem (1996) 67:1575-83. doi: 10.1046/j.1471-4159.1996.67041575.x

15. Pekny M, Nilsson M. Astrocyte activation and reactive gliosis. Glia (2005) 50:427-34. doi: 10.1002/glia.20207

16. Yang Z, Wang KK. Glial fibrillary acidic protein: from intermediate filament assembly and gliosis to neurobiomarker. Trends Neurosci. (2015) 38:364-74. doi: 10.1016/j.tins.2015.04.003

17. Riederer BM, Zagon IS, Goodman SR. Brain spectrin(240/235) and brain spectrin(240/235E): two distinct spectrin subtypes with different locations within mammalian neural cells. J Cell Biol. (1986) 102:2088-97. doi: $10.1083 /$ jcb.102.6.2088

18. Pike BR, Flint J, Dutta S, Johnson E, Wang KK, Hayes RL. Accumulation of non-erythroid alpha II-spectrin and calpain-cleaved alpha II-spectrin breakdown products in cerebrospinal fluid after traumatic brain injury in rats. J Neurochem. (2001) 78:1297-306. doi: 10.1046/j.1471-4159.2001.00510.x

19. Zoltewicz JS, Mondello S, Yang B, Newsom KJ, Kobeissy F, Yao C, et al. Biomarkers track damage after graded injury severity in a rat model of penetrating brain injury. J Neurotrauma (2013) 30:1161-9. doi: $10.1089 /$ neu.2012.2762

20. Mondello S, Robicsek SA, Gabrielli A, Brophy GM, Papa L, Tepas J, et al. alphaII-spectrin breakdown products (SBDPs): diagnosis and outcome in severe traumatic brain injury patients. J Neurotrauma (2010) 27:1203-13. doi: 10.1089/neu.2010.1278

21. Diaz-Arrastia R, Wang KK, Papa L, Sorani MD, Yue JK, Puccio $\mathrm{AM}$, et al. Acute biomarkers of traumatic brain injury: relationship between plasma levels of ubiquitin C-terminal hydrolase-L1 and glial fibrillary acidic protein. J Neurotrauma (2014) 31:19-25. doi: 10.1089/neu. 2013.3040

22. Chen S, Shi Q, Zheng S, Luo L, Yuan S, Wang X, et al. Role of alpha-IIspectrin breakdown products in the prediction of the severity and clinical outcome of acute traumatic brain injury. Exp Ther Med. (2016) 11:2049-53. doi: $10.3892 / \mathrm{etm} .2016 .3153$

23. Burda JE, Bernstein AM, Sofroniew MV. Astrocyte roles in traumatic brain injury. Exp Neurol. (2016) 275(Pt 3):305-15. doi: 10.1016/j.expneurol.2015.03.020

24. Saatman KE, Bozyczko-Coyne D, Marcy V, Siman R, McIntosh TK. Prolonged calpain-mediated spectrin breakdown occurs regionally following experimental brain injury in the rat. J Neuropathol Exp Neurol. (1996) 55:85060. doi: 10.1097/00005072-199607000-00010

25. McGinn MJ, Kelley BJ, Akinyi L, Oli MW, Liu MC, Hayes RL, et al. Biochemical, structural, and biomarker evidence for calpainmediated cytoskeletal change after diffuse brain injury uncomplicated by contusion. J Neuropathol Exp Neurol. (2009) 68:241-49. doi: 10.1097/NEN.0b013e3181996bfe

26. Zhang Z, Zoltewicz JS, Mondello S, Newsom KJ, Yang Z, Yang B, et al. Human traumatic brain injury induces autoantibody response against glial fibrillary acidic protein and its breakdown products. PLoS ONE (2014) 9:e92698. doi: 10.1371/journal.pone.0092698

27. Boutte AM, Deng-Bryant Y, Johnson D, Tortella FC, Dave JR, Shear DA, et al. Serum glial fibrillary acidic protein predicts tissue glial fibrillary acidic protein break-down products and therapeutic efficacy after penetrating ballistic-like brain injury. J Neurotrauma (2016) 33:147-56. doi: 10.1089/neu.2014.3672
28. Bogoslovsky T, Wilson D, Chen Y, Hanlon D, Gill J, Jeromin A, et al. Increases of plasma levels of glial fibrillary acidic protein, tau, and amyloid beta up to 90 days after traumatic brain injury. J Neurotrauma (2016) 34:66-73. doi: 10.1089/neu.2015.4333

29. Wang KK, Yang Z, Yue JK, Zhang Z, Winkler EA, Puccio AM, et al. Plasma anti-glial fibrillary acidic protein autoantibody levels during the acute and chronic phases of traumatic brain injury: a transforming research and clinical knowledge in traumatic brain injury pilot study. J Neurotrauma (2016) 33:1270-7. doi: 10.1089/neu.2015.3881

30. Williams AJ, Hartings JA, Lu XC, Rolli ML, Dave JR, Tortella FC. Characterization of a new rat model of penetrating ballistic brain injury. J Neurotrauma (2005) 22:313-31. doi: 10.1089/neu.2005.22.313

31. Williams AJ, Hartings JA, Lu XC, Rolli ML, Tortella FC. Penetrating ballisticlike brain injury in the rat: differential time courses of hemorrhage, cell death, inflammation, and remote degeneration. J Neurotrauma (2006) 23:1828-46. doi: $10.1089 /$ neu.2006.23.1828

32. Williams AJ, Ling GS, Tortella FC. Severity level and injury track determine outcome following a penetrating ballistic-like brain injury in the rat. Neurosci Lett. (2006) 408:183-8. doi: 10.1016/j.neulet.2006.08.086

33. Lu XC, Chen RW, Yao C, Wei H, Yang X, Liao Z, et al. NNZ-2566, a glypromate analog, improves functional recovery and attenuates apoptosis and inflammation in a rat model of penetrating ballistic-type brain injury. J Neurotrauma (2009) 26:141-54. doi: 10.1089/neu.2008.0629

34. Shear DA, Lu XC, Bombard MC, Pedersen R, Chen Z, Davis A, et al. Longitudinal characterization of motor and cognitive deficits in a model of penetrating ballistic-like brain injury. J Neurotrauma (2010) 27:1911-23. doi: 10.1089/neu.2010.1399

35. Shear DA, Lu XC, Pedersen R, Wei G, Chen Z, Davis A, et al. Severity profile of penetrating ballistic-like brain injury on neurofunctional outcome, bloodbrain barrier permeability, and brain edema formation. J Neurotrauma (2011) 28:2185-95. doi: 10.1089/neu.2011.1916

36. Mountney A, Boutte AM, Gilsdorf J, Lu XC, Tortella FC, Shear DA. Intravenous administration of simvastatin improves cognitive outcome following severe traumatic brain injury in rats. J Neurotrauma (2016) 33:1492-500. doi: 10.1089/neu.2015.4139

37. Mountney A, Boutte A, Cartagena CM, Flerlage WJ, Johnson D, Rho C, et al. Functional and molecular correlates following single and repeated rat closed-head concussion; indices of vulnerability following brain injury. J Neurotrauma (2017) 34:2768-89. doi: 10.1089/neu.2016.4679

38. Williams AJ, Wei HH, Dave JR, Tortella FC. Acute and delayed neuroinflammatory response following experimental penetrating ballistic brain injury in the rat. J Neuroinflammation (2007) $4: 17$. doi: 10.1186/1742-2094-4-17

39. Pike BR, Zhao X, Newcomb JK, Posmantur RM, Wang KK, Hayes RL. Regional calpain and caspase-3 proteolysis of alphaspectrin after traumatic brain injury. Neuroreport (1998) 9:2437-42. doi: 10.1097/00001756-199808030-00002

40. Smith DH, Chen XH, Pierce JE, Wolf JA, Trojanowski JQ, Graham DI, et al. Progressive atrophy and neuron death for one year following brain trauma in the rat. J Neurotrauma (1997) 14:715-27. doi: 10.1089/neu. 1997.14.715

41. Loane DJ, Kumar A, Stoica BA, Cabatbat R, Faden AI. Progressive neurodegeneration after experimental brain trauma: association with chronic microglial activation. J Neuropathol Exp Neurol. (2014) 73:14-29. doi: 10.1097/NEN.0000000000000021

42. Wang KK. Calpain and caspase: can you tell the difference? Trends Neurosci. (2000) 23:20-6.

43. Azuma M, Shearer TR. The role of calcium-activated protease calpain in experimental retinal pathology. Surv Ophthalmol. (2008) 53:150-63. doi: 10.1016/j.survophthal.2007.12.006

44. Valiyaveettil M, Alamneh YA, Wang Y, Arun P, Oguntayo S, Wei Y, et al. Cytoskeletal protein alpha-II spectrin degradation in the brain of repeated blast exposed mice. Brain Res. (2014) 1549:32-41. doi: 10.1016/j.brainres.2013.12.031

45. Newcomb JK, Kampfl A, Posmantur RM, Zhao X, Pike BR, Liu SJ, et al. Immunohistochemical study of calpain-mediated breakdown products to alpha-spectrin following controlled cortical impact injury in the rat. J Neurotrauma (1997) 14:369-83. doi: 10.1089/neu.1997.14.369 
46. Yao C, Williams AJ, Ottens AK, Lu XC, Liu MC, Hayes RL, et al. P43/pro-EMAPII: a potential biomarker for discriminating traumatic versus ischemic brain injury. J Neurotrauma (2009) c26:1295-305. doi: 10.1089/neu.2008-081110.1089/neu.2008.0811

47. Ringger NC, O'Steen BE, Brabham JG, Silver X, Pineda J, Wang $\mathrm{KK}$, et al. A novel marker for traumatic brain injury: CSF alphaIIspectrin breakdown product levels. J Neurotrauma (2004) 21:1443-56. doi: 10.1089/neu.2004.21.1443

48. Zoltewicz JS, Scharf D, Yang B, Chawla A, Newsom KJ, Fang L. Characterization of antibodies that detect human GFAP after traumatic brain injury. Biomark Insights (2012) 7:71-9. doi: 10.4137/BMI.S9873

49. Pineda JA, Lewis SB, Valadka AB, Papa L, Hannay HJ, Heaton SC, et al. Clinical significance of alphaII-spectrin breakdown products in cerebrospinal fluid after severe traumatic brain injury. J Neurotrauma (2007) 24:354-66. doi: 10.1089/neu.2006.003789

50. Papa L, Lewis LM, Falk JL, Zhang Z, Silvestri S, Giordano P, et al. Elevated levels of serum glial fibrillary acidic protein breakdown products in mild and moderate traumatic brain injury are associated with intracranial lesions and neurosurgical intervention. Ann Emerg Med. (2012) 59:471-83. doi: 10.1016/j.annemergmed.2011.08.021

51. Okonkwo DO, Yue JK, Puccio AM, Panczykowski DM, Inoue T, McMahon PJ, et al. GFAP-BDP as an acute diagnostic marker in traumatic brain injury: results from the prospective transforming research and clinical knowledge in traumatic brain injury study. J Neurotrauma (2013) 30:1490-7. doi: 10.1089/neu.2013.2883

52. McMahon PJ, Panczykowski DM, Yue JK, Puccio AM, Inoue T, Sorani MD, et al. Measurement of the glial fibrillary acidic protein and its breakdown products GFAP-BDP biomarker for the detection of traumatic brain injury compared to computed tomography and magnetic resonance imaging. J Neurotrauma (2015) 32:527-33. doi: 10.1089/neu.2014.3635

53. Wilde EA, McCauley SR, Kelly TM, Levin HS, Pedroza C, Clifton GL, et al. Feasibility of the neurological outcome scale for traumatic brain injury (NOSTBI) in adults. J Neurotrauma (2010) 27:975-81. doi: 10.1089/neu.2009.1193
54. McCauley SR, Wilde EA, Moretti P, Macleod MC, Pedroza C, Drever P, et al. Neurological outcome scale for traumatic brain injury: III. Criterionrelated validity and sensitivity to change in the NABIS hypothermiaII clinical trial. I Neurotrauma (2013) 30:1506-11. doi: 10.1089/neu. 2013.2925

55. DeDominicis K, Hwang H, Deng-Bryant Y, Shear D, Boutte A, Cartagena C. Regional acute and subacute alterations in Gfap, spectrin, and breakdown products following penetrating ballistic-like Tbi in rats. J Neurotrauma (2016) 33:A16-7.

56. DeDominicis K., Cartagena C, Hwang H, Shear D, Boutte A. Longitudinal profile of Gfap, alpha-Ii-spectrin, and their breakdown products in rat Csf after probe insertion or penetrating Tbi. J Neurotrauma (2017) 34:A19-20

Disclaimer: Research was performed under an animal use protocol approved by the Walter Reed Army Institute of Research/Naval Medical Research Center IACUC. Material has been reviewed by the Walter Reed Army Institute of Research. There is no objection to its presentation and/or publication. The opinions or assertions contained herein are the private views of the author, and are not to be construed as official, or as reflecting true views of the Department of the Army or the Department of Defense.

Conflict of Interest Statement: The authors declare that the research was conducted in the absence of any commercial or financial relationships that could be construed as a potential conflict of interest.

Copyright (c) 2018 DeDominicis, Hwang, Cartagena, Shear and Boutté. This is an open-access article distributed under the terms of the Creative Commons Attribution License (CC BY). The use, distribution or reproduction in other forums is permitted, provided the original author(s) and the copyright owner(s) are credited and that the original publication in this journal is cited, in accordance with accepted academic practice. No use, distribution or reproduction is permitted which does not comply with these terms. 